\title{
Recurrent Extragonadal Seminoma
}

National Cancer Institute

\section{Source}

National Cancer Institute. Recurrent Extragonadal Seminoma. NCI Thesaurus. Code C115428.

The reemergence of extragonadal seminoma after a period of remission. 